\title{
Parameterisation and Modelling of Large Off-Road Tyres for Handling Analyses
}

Yasheen Babulal

M. Joachim Stallmann

P. Schalk Els*

Department of Mechanical and Aeronautical Engineering, University of Pretoria, cnr Lynwood Road and Roper Street,

Pretoria 0002, South Africa

* Corresponding author, Tel +27 124202045

E-mail addresses: yasheen.babulal@gmail.com (Y. Babulal), joachim@stallmann.co.za (M.J. Stallmann),

schalk.els@up.ac.za (P.S. Els)

\section{Abstract}

Very few off-road vehicles are used exclusively under off-road conditions. Good off-road mobility does however dictate large high aspect ratio tyres, with aggressive tread, soft suspension for good ride comfort as well as other vehicle parameters including large ground clearance and the related high centre of mass. This often results in less-than-satisfactory handling and high rollover propensity when operating on hard terrains.

In order to simulate vehicle handling and roll over propensities, tyre characteristics in the form of side-force versus slip-angle curves, as well as suitable tyre models are required. For large offroad tyres these characteristics are not readily available. Tyre manufacturers either do not have these characteristics, or do not openly publish them. Similarly, the majority of tyre models have been developed and validated for passenger car tyres and their applicability to large tyres are unknown. The purpose of this study is to measure side-force versus slip-angle characteristics for a Michelin 16.00R20 XZL tyre - typically used on off-road trucks. The data is used to parameterise a Fiala, UA (University of Arizona), Pacejka89 (ADAMS View implementation) and 
FTire model. Simulation results are compared to both steady state and dynamic handling test results to determine the accuracy of these models.

\section{Highlights:}

- Large off-road tyre measured side-force versus slip-angle characteristic curves.

- Parameterisation of FTire, Pacejka89, Fiala and UA tyre models for handling.

- Model verification for steady state lateral force vs. slip angle

- Model verification for dynamic conditions (double lane change)

Keywords: Large off-road tyre, side-force, slip-angle, Michelin XZL, handling tyre model, parameterisation, Pacejka89, Fiala, UA, FTire.

\section{Notation}

$\begin{array}{lll}\mathrm{a}_{0} \ldots \mathrm{a}_{13} & - & \text { Lateral coefficients in 'Magic Formula' } \\ \mathrm{B} & - & \text { Stiffness factor in 'Magic Formula' } \\ \mathrm{BCD} & - & \text { Slope at zero slip-angle in 'Magic Formula' } \\ \mathrm{C} & - & \text { Shape factor in 'Magic Formula' } \\ \mathrm{CD} & - & \text { Product of } \mathrm{C} \text { and } \mathrm{D} \text { as used in 'Magic Formula' } \\ \mathrm{C}_{\mathrm{Fy}} & - & \text { Lateral tyre stiffness } \\ \mathrm{C}_{\mathrm{s}} & - & \text { Critical longitudinal slip } \\ \mathrm{C}_{\alpha} & - & \text { Fiala \& UA tyre model cornering stiffness' } \\ \mathrm{D} & - & \text { Peak factor in 'Magic Formula' } \\ \mathrm{E} & - & \text { Curvature factor in 'Magic Formula' } \\ \mathrm{F}_{\mathrm{y}} & & \text { Tyre lateral force }\end{array}$




\begin{tabular}{|c|c|c|}
\hline Notati & & \\
\hline $\mathrm{F}_{\mathrm{z}}$ & - & Tyre vertical force \\
\hline LI & - & Load index of tyre \\
\hline$l_{\mathrm{n}}$ & - & Contact patch length \\
\hline$S_{h}$ & - & Horizontal shift in 'Magic Formula' \\
\hline $\mathrm{S}_{\mathrm{s}}$ & - & Longitudinal slip ratio \\
\hline $\mathrm{S}_{\mathrm{s} \alpha}$ & - & Resultant slip due to longitudinal slip and slip-angle \\
\hline$S_{v}$ & - & Vertical shift in 'Magic Formula' \\
\hline$S_{\alpha}$ & - & Lateral slip due to slip-angle \\
\hline $\mathrm{S}_{\alpha c}$ & - & Critical lateral slip ratio \\
\hline $\mathrm{X}_{1}$ & - & Composite angle in 'Magic Formula' \\
\hline$\alpha$ & - & Tyre slip-angle \\
\hline$\alpha_{\text {critical }}$ & - & Critical lateral slip-angle \\
\hline$\gamma$ & - & Camber angle \\
\hline$\mu$ & - & Coefficient of friction \\
\hline$\mu_{\text {current }}$ & - & Current friction coefficient of slip \\
\hline$\mu_{\mathrm{d}}$ & - & Dynamic coefficient of friction \\
\hline$\mu_{\mathrm{s}}$ & - & Static coefficient of friction \\
\hline$\mu_{\mathrm{x}}$ & - & Friction coefficient in the longitudinal direction \\
\hline$\mu_{\mathrm{y}}$ & - & Friction coefficient in the lateral direction \\
\hline$\sigma_{\alpha}$ & - & Relaxation length \\
\hline
\end{tabular}




\section{Introduction}

Air filled rubber tyres are used in many applications, ranging from bicycles, motorcycles, all terrain vehicles (ATV's), passenger cars, sport utility vehicles (SUV's), busses, trucks, tractors, military vehicles and aeroplanes. Very few off-road vehicles are used exclusively under off-road conditions. Good off-road mobility does however dictate large high aspect ratio tyres, with aggressive tread, soft suspension for good ride comfort as well as other vehicle parameters including large ground clearance and the related high centre of mass. This often results in lessthan-satisfactory handling and high rollover propensity when operating on hard terrains. When travelling, these vehicles do not always encounter a straight path. They more often than not encounter curved paths and need to be able to negotiate them. When a tyre negotiates a curved path, it is its lateral characteristics that are currently at 'work'. This study focuses on measuring and modelling these lateral characteristics for large off-road tyres.

According to Haney [1] "a modern pneumatic tyre is a complicated composite construction of strong, light polymer fibres held together in a matrix of visco-elastomeric polymers - rubbers". According to Pacejka [2] the complexity of the structure and behaviour of the tyre is such that no complete and satisfactory theory has yet been propounded. Both of the above descriptions indicate that the tyre is a complex entity, and is an area that is still to be fully understood. It therefore forms an excellent basis for research and development.

To determine the tyre characteristics laboratory test rigs or mobile tyre test rigs are used. Laboratory type tyre testers comprise of Drum type [3], Belt type (MTS Flat-Trac system) [4] and full vehicle indoor test rigs (MTS Flat-Trac Roadway) [4]. An example of a mobile tyre tester is the TU-Delft tyre test trailer [2], used to test passenger and motorcycle tyres. Several examples of tyre testers utilised to characterise agricultural tyres on soft terrains are given by Kutzbach et al [5]. One of the main significant differences between mobile and laboratory tyre testers is that 
mobile tyre testers utilise the actual road surface that the tyres are used on, whereas laboratory tyre testers utilise an artificially created road surface on a drum or on a steel belt.

\section{Tyre models}

Many tyre models exist that can potentially be used for handling analysis on hard surfaces. In this study, four popular tyre models, namely Fiala, University of Arizona (UA), Pacejka '89 and FTire, were parameterised to describe lateral tyre behaviour.

\subsection{Fiala tyre model}

The Fiala tyre model is a physics-based tyre model [6]. The tyre carcass is modelled as a beam on an elastic foundation in the lateral direction. Elastic brush elements provide the contact between the carcass and the road. Analytical assumptions are derived for the steady state slip characteristics and these form the basis for calculating the longitudinal and lateral forces. The model assumes that the tyre contact patch is rectangular with a uniform pressure distribution. Camber effects are neglected in the Fiala tyre model. To determine the lateral force, Fiala defines a critical lateral slip angle as:

$$
\alpha_{\text {critical }}=\arctan \left(\frac{3 * \mu_{\text {current }} *\left|F_{Z}\right|}{C_{\alpha}}\right)
$$

Where the cornering stiffness, $C_{\alpha}$, is defined as

$$
C_{\alpha}=\left.\frac{d F_{y}}{d \alpha}\right|_{\propto=0}
$$

The current friction coefficient of slip, $\mu_{\text {current }}$, is a function of the static, $\mu_{s}$, and dynamic, $\mu_{d}$, friction coefficients as well as the longitudinal slip state of the tyre. The current friction coefficient is given by:

$$
\mu_{\text {current }}=\mu_{s}-\left(\mu_{s}-\mu_{d}\right) * \sqrt{S_{s}^{2}+\tan ^{2}(\alpha)}
$$

The lateral force is then calculated for the elastic deformation state, $|\alpha| \leq \alpha_{\text {critical }}$, by evaluating: 


$$
F_{y}=-\mu_{\text {current }} *\left|F_{z}\right| *\left(1-H^{3}\right) * \operatorname{sign}(\alpha)
$$

Where

$$
H=1-\frac{C_{\alpha^{*}}|\tan (\alpha)|}{3 * \mu_{\text {current }} *\left|F_{z}\right|}
$$

And for the sliding state, $|\alpha|>\alpha_{\text {critical }}$ :

$$
F_{y}=-\mu_{\text {current }} *\left|F_{z}\right| * \operatorname{sign}(\alpha)
$$

To improve the transient behaviour of the tyre model a relaxation length , $\sigma_{\alpha}$, is introduced as:

$$
\sigma_{\alpha}=\frac{C_{\alpha}}{C_{F y}}
$$

\subsection{UA tyre model}

The University of Arizona (UA) tyre model was originally developed by Nikravesh and Grim [6]. The UA Tyre model calculates the forces at the ground contact point as a function of the kinematic states of the tyre, defined by the longitudinal and lateral slip, camber angle, deflection and the deflection rate. The UA tyre model includes relaxation effects, both in the longitudinal and lateral direction. The effect of camber on the lateral and longitudinal force are included in this model. Camber effects are however not included in the present study and will thus not be discussed in this paper. The lateral slip ratio due to the lateral slip, $S_{\alpha}$, is defined as:

$$
S_{\alpha}=\left\{\begin{array}{ll}
|\tan \alpha| & \text { during braking } \\
\left(1-S_{s}\right)|\tan \alpha| & \text { during traction }
\end{array}\right\}
$$

Where $S_{\alpha}$ is limited to be smaller than 1 . A resultant slip ratio is then defined as:

$$
S_{s \alpha}=\sqrt{S_{s}^{2}+S_{\alpha}^{2}}
$$

Where $S_{s \alpha}$ is limited to be smaller than 1 . A linear relationship between the resultant slip ratio and the friction coefficient is described as :

$$
\mu_{\text {current }}=\mu_{s}-\left(\mu_{s}-\mu_{d}\right) * S_{s \alpha}
$$

The lateral and longitudinal friction coefficients are defined by a friction circle and are described as: 


$$
\left(\frac{\mu_{x}}{\mu_{\text {current }}}\right)^{2}+\left(\frac{\mu_{y}}{\mu_{\text {current }}}\right)^{2}=1
$$

A critical lateral slip value, $S_{\alpha c}$, is defined to distinguish between the elastic deformation and complete sliding phases. The critical slip value is given by:

$$
S_{\alpha c}=\frac{C_{S}}{C_{\alpha}} \sqrt{\left(\frac{3 \mu_{\text {current }} F_{z}}{C_{S}}\right)^{2}-S_{S}^{2}}
$$

The lateral force during the elastic phase, $S_{\alpha} \leq S_{\alpha c}$ is given by:

$$
F_{y}=C_{\alpha} S_{s} l_{n}^{2}+\mu_{y} F_{z}\left(1-3 l_{n}^{2}+2 l_{n}^{3}\right)
$$

Where $l_{n}$ is the non-dimensional contact patch length given by:

$$
l_{n}=1-\frac{\sqrt{\left(3 \mu F_{z}\right)^{2}\left(C_{s}^{2} S_{S}^{2}+C_{\alpha}^{2} S_{\alpha}^{2}\right)}}{\left(3 \mu F_{z}\right)^{2}}
$$

The lateral force during complete sliding, $S_{\alpha}>S_{\alpha c}$, is given by :

$$
F_{y}=\mu_{y} F_{z} \quad(15)
$$

\subsection{Pacejka 89 tyre model}

The Pacejka 89 tyre model as implemented in ADAMS [6] is based on the 'Magic Formula' curve fit, as described by Bakker et al [7]. The 'Magic Formula' is used to calculate steady state force and moment characteristics by means of formulas and interpolation schemes, for which the parameters are determined by curve-fitting to experimental data. The parameters in the 'Magic Formula' model have physical significance, and can be related to measured characteristics of the tyre.

The lateral force is defined as:

$$
F_{y}=D \sin \left[C \tan ^{-1}\left\{B X_{1}-E\left(B X_{1}-\tan ^{-1}\left(B X_{1}\right)\right)\right\}\right]+S_{v}
$$

An illustration of the curve and the various coefficients are given in Figure 1. 


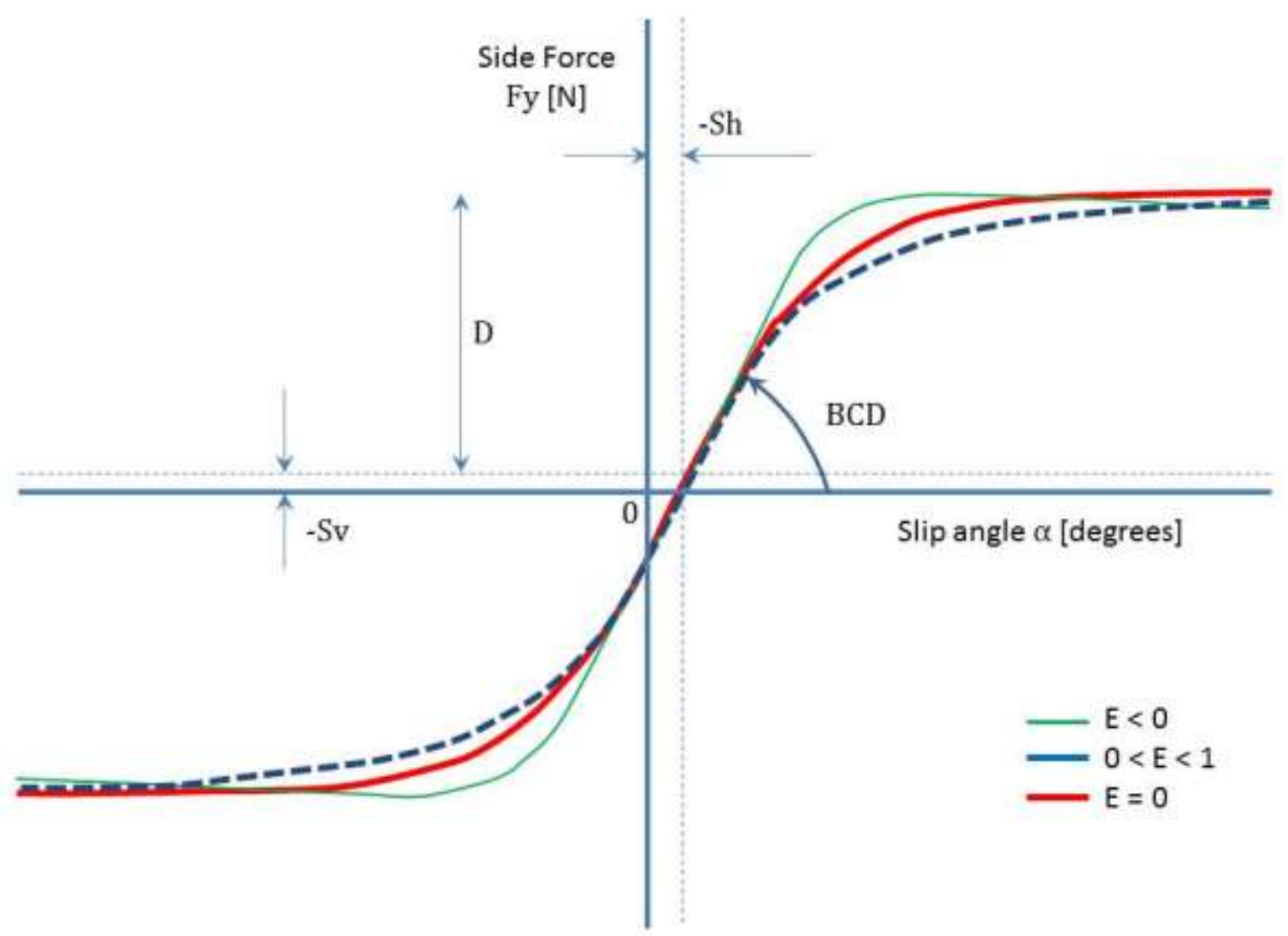

Figure 1: Illustration of coefficients defined in the 'Magic Formula' (adapted from Bakker et al [7])

The various coefficients are defined as follows:

$F_{y}$ is the Lateral force generated by the tyre, and $\alpha$ is the slip-angle.

$D$ is the peak value of the lateral force:

$$
D=a_{1} F_{z}^{2}+=a_{2} F_{z}
$$

C is the shape factor:

$$
C=a_{0}
$$

BCD is the slope at zero slip-angle:

$$
B C D=a_{3} \sin \left(2 \tan ^{-1}\left(F_{z} / a_{4}\right)\right)\left(1-a_{5}|\gamma|\right)
$$

$B$ is the stiffness factor:

$$
B=B C D / C D \quad(20)
$$

$E$ is the curvature factor: 


$$
E=a_{6} F_{z}+a_{7}
$$

The horizontal shift is defined as:

$$
S_{h}=a_{9} F_{z}+a_{10}+a_{8} \gamma
$$

The vertical shift is defined as:

$$
S_{v}=a_{11} F_{z} \gamma+a_{12} F_{z}+a_{13}
$$

Finally the slip angle is defined as:

$$
X_{1}=\propto+S_{h}
$$

\subsection{FTire model}

FTire (Flexible Structure Tyre Model) is a full 3D nonlinear in-plane and out-of-plane tyre model based on a structural dynamics approach [8,9]. FTire was developed for vehicle comfort simulations and the prediction of the tyre forces on roads with short wave-length obstacles but can also be used for handling simulations. The tyre model describes the tyre belt as a flexible ring that can flex and extend in the radial, tangential and lateral directions while the lateral force is determined by the interaction between the belt and the road. The parameterisation and validation of an FTire model for ride, based on the same tyre and a test trailer used in this study, was presented with extensive detail in [10]. This ride model was used as the starting point for the parameterisation of the handling properties.

\section{Experimental test setup and results}

\subsection{Equipment: Large Tyre Tester}

A large tyre test trailer was utilised to perform the tests on the Michelin 16.00 R20 XZL tyre. The test equipment, as well as an ADAMS model of the tyre test trailer, is described in detail by Stallmann et al [11]. 
The Tyre Tester as depicted in Figure 2 is a large rigid "trailer" with two tyres mounted on adjustable hubs. In this configuration, its unladen mass is approximately $4800 \mathrm{~kg}$. It requires a heavy tow vehicle to pull it over the relevant test surface. The trailer is $4648 \mathrm{~mm}$ long, $3052 \mathrm{~mm}$ wide and $2387 \mathrm{~mm}$ high. The Tyre Tester can be loaded with steel ballast plates, therefore allowing the static vertical load on the tyre to be varied discretely as required.

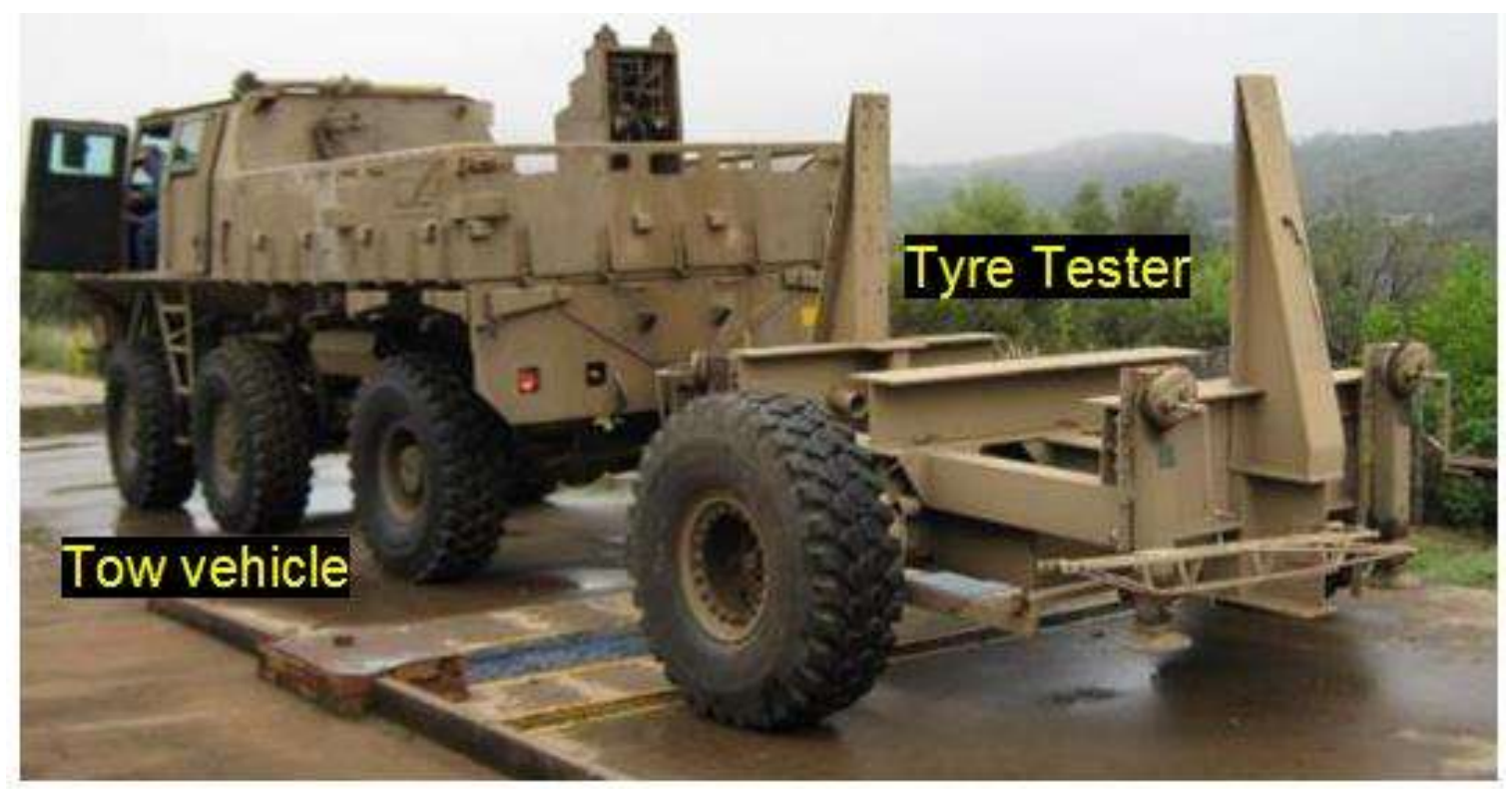

Figure 2: Tow vehicle and Tyre Tester

The slip-angle of each wheel can be adjusted manually in fixed increments of approximately two degrees. The total range of adjustment is $-2^{\circ}$ to $+10^{\circ}$. The camber of the tyre is fixed and is nonadjustable. The right-hand side hub is mounted on a sub frame. The mainframe and sub frame are inter-connected via the six load cells. The six load cells thus measure the forces on the right tyre. The forces are transmitted from the tyre via the of the wheel rim, wheel hub, sub frame, then onto the main frame via the load cells. The load cells measure tension-compression only and are mounted in spherical bearings (rod-ends) to eliminate bending loads.

The Tyre Tester is equipped with the following relevant instrumentation for the track tests:

- Six permanently installed load cells that the following functionality: 
- Two lateral load cells which are used to measure the lateral force on the tyre.

- Three vertical load cells which are used to measure the vertical input to the tyre.

- A single longitudinal load cell which is used to determine the longitudinal force on the tyre.

- Accelerometers measuring in the vertical and lateral directions, at specific points on the Tyre Tester.

- A Corsys Datron Correvit® S-HR optical sensor [12], used to measure high resolution slip angle (range $-15^{\circ}$ to $+15^{\circ}$ ) and longitudinal speed. The specification on the angle resolution for the sensor is $<0.01^{\circ}$ with and angle accuracy is $< \pm 0.1^{\circ}$.

- Differential GPS (Global Positioning System) for speed and accurate position.

- A Somat e-DAQ data acquisition system that sampled all the data at $1000 \mathrm{~Hz}$.

\subsection{Test tyre detail}

The Michelin 16.00R20 XZL tyre is used for general purpose under on and off-road conditions in the military and earth moving industries. It has a coarse tread pattern to enable traction under off-road conditions. The tread blocks on this tyre assist in vertical climbing of off-road obstacles as often encountered in rocky off-road terrain. The tyre pressure used for this study was set to $300 \mathrm{kPa}$.

\subsection{Track Testing conducted at Gerotek Test Facilities}

Two sets of tyre tests were performed. The lateral tyre characterisation tests were performed to determine the side-force slip-angle characteristic of the test tyre. The results of these tests were presented in Stallmann et al [11]. The second test was a dynamic validation test in the form of a double lane change. During this test the dynamic change of side-force and slip-angle could be captured with respect to time. 
Tests were performed at Gerotek Test Facilities [13] west of Pretoria in South Africa. The tyre tests were performed on the Straight Track on a brushed concrete test surface. It is one kilometre in length, and is level in the lateral and longitudinal direction [13].

\subsection{Side-force versus slip-angle testing procedure}

To obtain side-force versus slip-angle test results the slip-angle on the tyre test trailer was set to a fixed slip angle. The tow vehicle with the tyre tester was then accelerated from rest until a constant speed of $12 \mathrm{~km} / \mathrm{h}$ was reached. Pacejka [2] has shown that the test speed has a negligible effect on the side-force versus slip-angle tyre characteristic for large tyres and in dry test conditions. The constant speed of $12 \mathrm{~km} / \mathrm{h}$ was achieved by selecting a low gear on the tow vehicle, and using maximum throttle until the speed stabilised against the engines speed governor. The test run continued for approximately 20 seconds which allowed for sufficient steady state data to be captured. The slip-angle was then manually adjusted and the process was repeated. Slip-angle tests were conducted at slip angle settings of $-2^{\circ}, 0^{\circ}, 2^{\circ}, 4^{\circ}, 6^{\circ}, 8^{\circ}$ and $10^{\circ}$ while the actual slip angle was measured, together with all the other parameters using the slip angle sensor.

Two test runs were conducted per slip-angle to reduce the probability of erroneous and outlying data and also increase the confidence in the data. Too many runs can however not be performed due to extensive wear and heat generation of the tyres, especially at the large slip-angles.

The load condition was then changed by adding steel ballast plates and the testing was repeated as per the process above. The tyre was tested at $36 \%, 60 \%$, and $82 \%$ of the maximum rated wheel load of $6595 \mathrm{~kg}$, indicated as percentage of the Load Index (\%LI). Figure 3 shows the 


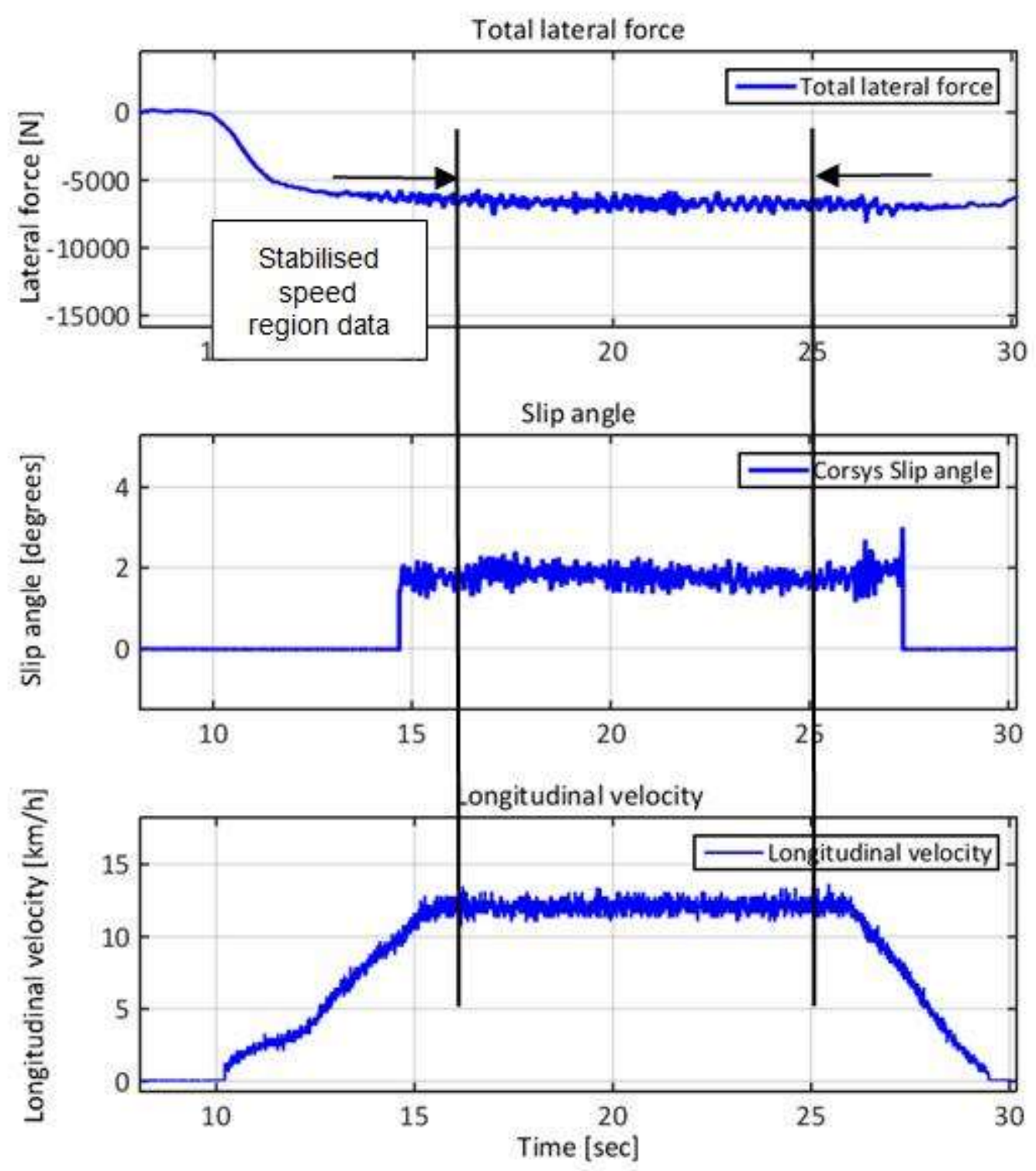

Figure 3: Data of total lateral force, slip-angle and speed

typical data from a single test run with the slip-angle set to $2^{\circ}$. The graphs depict the following data in order from top to bottom:

- Total lateral force, which equals the sum of the two lateral load cells.

- The tyre slip-angle, as measured by the Corsys slip-angle sensor.

- Longitudinal speed of the tyre test rig. 
An average value was taken over the stabilized speed region of the lateral force and the slipangle of the test tyre. The slip angle sensor measured a fixed offset of 0.7 degrees. This offset can be associated to the mounting of the sensor. The third test of the third load case is omitted from the data set due to technical difficulties during the test run. The side-force and slip-angle measurement results are shown in Table 1 and Figure 5.

Table 1: Michelin Tyre: Side-force \& Slip-angle data

\begin{tabular}{|c|c|c|c|c|c|}
\hline \multicolumn{2}{|c|}{ Load 1 (36\% LI or 2385kg) } & \multicolumn{2}{c|}{ Load 2 (60\% LI or 3940kg) } & \multicolumn{2}{c|}{ Load 3 (82\% LI or 5390kg) } \\
\hline Slip-angle ( $\left.{ }^{\circ}\right)$ & Side-force (N) & Slip-angle ( $\left.{ }^{\circ}\right)$ & Side-force (N) & Slip-angle ( $\left.{ }^{\circ}\right)$ & Side-force (N) \\
\hline-1.7 & -7884 & -1.6 & -10829 & -1.7 & -5125 \\
\hline 0.0 & -1099 & 0.0 & -1129 & 0.0 & 959 \\
\hline 2.3 & 9810 & 2.3 & 12903 & - & - \\
\hline 4.2 & 15989 & 4.2 & 22744 & 4.1 & 25385 \\
\hline 5.8 & 18434 & 5.9 & 26419 & 5.8 & 31066 \\
\hline 7.3 & 19283 & 7.4 & 27914 & 7.2 & 33196 \\
\hline 8.0 & 19460 & 8.7 & 28405 & 8.5 & 34154 \\
\hline
\end{tabular}

\section{Parameterisation and correlation of tyre models}

As the focus of this study is on side-force versus slip-angle tyre characteristics, the influential tyre model parameters relevant to the lateral characteristics of the tyre are discussed in this paper.

The lateral tyre stiffness is required to determine the relaxation length. This stiffness was determined by pulling the Tyre Tester laterally, and allowing the tyre to deflect laterally. The lateral displacement was measured, and the lateral load cells on the Tyre Tester measured the 
tyre lateral force. The lateral tyre stiffness was determined to be $223.1 \mathrm{~N} / \mathrm{mm}$. The vertical tyre stiffness and vertical tyre damping were calculated as described by Stallmann et al [11].

The tyre models are divided into two groups namely:

i) Tyre models where the cornering stiffness is independent of the vertical load (Fiala and UA tyre)

ii) Models that take the effect of the normal load on the cornering stiffness into account (Pacejka 89 and FTire model).

\subsection{Fiala tyre model parameterisation}

The lateral behaviour of the Fiala model is determined by the cornering stiffness, $C_{\alpha}$, static friction coefficient, $\mu_{\max }$, sliding friction coefficient, $\mu_{\min }$, and the lateral relaxation length, $\sigma_{\alpha}$. The cornering stiffness is defined as the partial derivative of lateral force with respect to slip-angle at zero slip-angle.

Table 2 shows the calculated cornering stiffness values. It was noted by Blundell [14] that the Fiala model only contains a single value for cornering stiffness, whereas in reality there are different cornering stiffnesses for different vertical wheel loads, as seen in Blundell [14] therefore used an average value, so that tyre model comparisons could be conducted. Hence an average $C_{\alpha}$ parameter was computed for the Fiala tyre model.

The sliding friction coefficient was calculated to be 0.72 . The static friction coefficient was determined by adjusting the friction coefficient until the best correlation between the measured and simulated lateral force results was obtained. The best correlation was obtained with a static friction coefficient of 0.8 .The relaxation length is defined as a ratio between the cornering 
stiffness (in Newton per radian), and the tyre lateral stiffness. The relaxation length was calculated to be $1.438 \mathrm{~m}$.

Table 2: Fiala parameters

\begin{tabular}{|c|c|c|c|c|c|}
\hline Load case & Load (\%LI) & Load $(\mathbf{k g})$ & $\mathrm{C}_{\alpha}\left[\mathbf{N} /{ }^{\circ}\right]$ & $\mu_{\text {slip }}$ & $\sigma_{\alpha}[\mathrm{m}]$ \\
\hline 1 & 36 & 2385 & 4743.0 & 0.79 & 1.22 \\
\hline 2 & 60 & 3940 & 6100.9 & 0.71 & 1.57 \\
\hline 3 & 82 & 5390 & 5957.6 & 0.65 & 1.53 \\
\hline Average & $\mathbf{5 9 . 3}$ & $\mathbf{3 9 0 5}$ & $\mathbf{5 6 0 0 . 5}$ & $\mathbf{0 . 7 2}$ & $\mathbf{1 . 4 4}$ \\
\hline
\end{tabular}

\subsection{UA tyre model parameterisation}

Similar to the Fiala tyre model, the UA tyre model uses the same cornering stiffness parameters as well as the friction coefficients and the relaxation length indicated in Table 2.

These parameters were substituted into the ADAMS Fiala and UA Tyre model tyre-definition files respectively and "simulated" using the "Tire Testrig" application in ADAMS. The "Tire Testrig" was used to simulate the steady state tyre behaviour, for all three load conditions, for slip angles between -2 and 9 degrees. The resultant fits are indicated, together with the measured results, in Figure 4

The Fiala fits indicate a result similar to that observed by Blundell [14], where the Fiala model underestimates lateral forces where high slip-angles coincide with higher vertical wheel loads. The UA tyre model shows a similar result to the Fiala tyre model. 


\subsection{Pacejka 89 tyre model parameterisation}

The parameterisation of the Pacejka 89 tyre model was done in two stages. In the first stage the horizontal and vertical shift of the test data was assumed to be zero. From the test data the stiffness, peak and curvature factors were determined. The factors where then fitted with Eqs. 17 to 21 . The second parameterisation stage utilized the acquired coefficients, $a_{0}$ to $a_{13}$, as initial conditions in an optimisation process. The horizontal and vertical shift coefficients were included in the optimisation technique. By limiting the upper and lower bounds the behaviour of the model was controlled for slip ranges outside of the measurement conditions. A summary of the calculated Pacejka 89 lateral coefficients is shown in Table3. The measured and predicted tyre behaviour is shown in Figure 4.

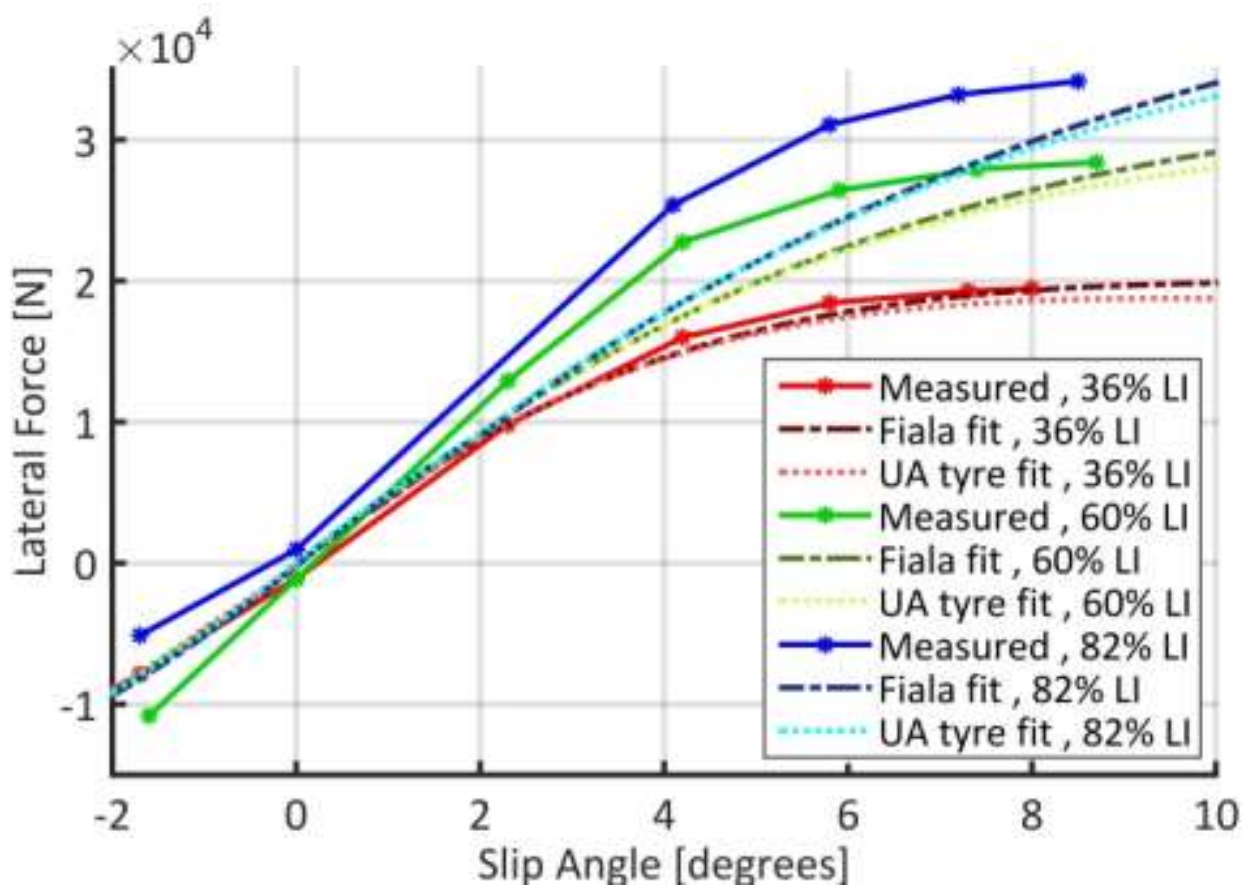

Figure 4: Side force vs. slip relationship for load independent cornering stiffness models 
Table 3: Pacejka 89 lateral coefficients

\begin{tabular}{|c|c|}
\hline Lateral coefficients & Michelin XZL coefficients \\
\hline$a_{0}$ & 1.2001 \\
\hline$a_{1}$ & 9.7626 \\
\hline$a_{2}$ & 1866.7348 \\
\hline$a_{3}$ & 6438.6892 \\
\hline $\mathbf{a}_{4}$ & 60.4195 \\
\hline$a_{5}$ & 0 \\
\hline$a_{6}$ & 0.1216 \\
\hline$a_{7}$ & 1.9346 \\
\hline$a_{8}$ & 0 \\
\hline$a_{9}$ & 0.0094 \\
\hline$a_{10}$ & -0.3520 \\
\hline$a_{11}$ & 0 \\
\hline$a_{12}$ & 46.1658 \\
\hline$a_{13}$ & -48.4015 \\
\hline
\end{tabular}

\subsubsection{FTire parameterisation}

FTire/fit is used to parameterise an FTire model using measured test results. The FTire model developed for ride [10] was used as a starting point for fitting the lateral properties. The measured side force slip test data was converted into the TYDEX file format and imported into FTire/fit. The belt out of plane bending stiffness, lateral tyre stiffness and friction characteristics were optimised. The friction coefficients, as used by FTire, are dependent on the sliding velocity, ground pressure and the tread rubber temperature. No temperature data was available for this study and default 
values were assumed. The model was tweaked by manually adjusting the tread behaviour and the parameters altering the stiffness progressivity. The results of the measured and predicted lateral tyre forces are shown in Figure 5.

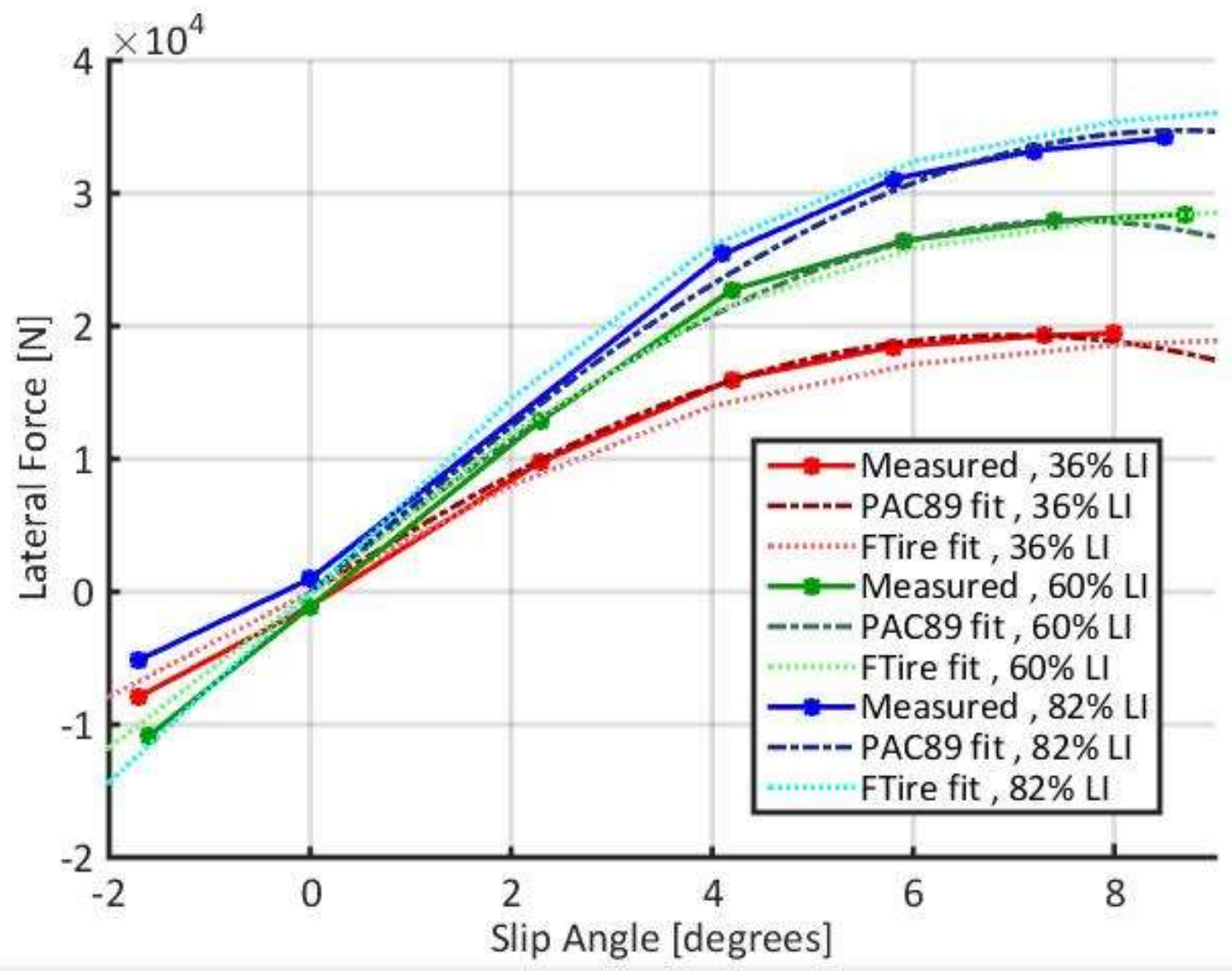

Figure 5: Side force vs. slip relationship for load dependent cornering stiffness models

Figure 5 shows that both the Pacejka 89 and FTire models accurately capture the tyre behaviour for the test conditions. The Pacejka 89 model shows better correlation with the measurements, for the $36 \% \mathrm{LI}$ test condition than the FTire model. At high slip angles the predicted lateral force of the Pacejka 89 model decreases while the measurements show a slight increase. Care must be taken for simulations where large slip angles are anticipated to ensure accurate simulation results. 


\subsection{Tyre model Validation}

A double lane change test, based on the ISO 3888-1 standard track layout [15], was performed by towing the Tyre Tester behind a tow vehicle. The slip-angle on the Tyre Tester was set to zero degrees. The GPS co-ordinates of the actual path traversed by the tow hook of the Tyre Tester was recorded during the test using a VBOX III Differential GPS with base station, for highly accurate measurement. The positional accuracy of the system is specified to be $20 \mathrm{~mm}$ by the manufacturer [16] although more realistic real-life measurements of around $100 \mathrm{~mm}$ can be achieved. This data was used as a spline to drive the ADAMS model Tyre Tester, through the measured path obtained during each test. In this manner the simulation data could be compared directly with the measured track data.

Each tyre model was simulated through the measured lane change track. The simulated yaw velocity and lateral tyre force is compared to the measured data.

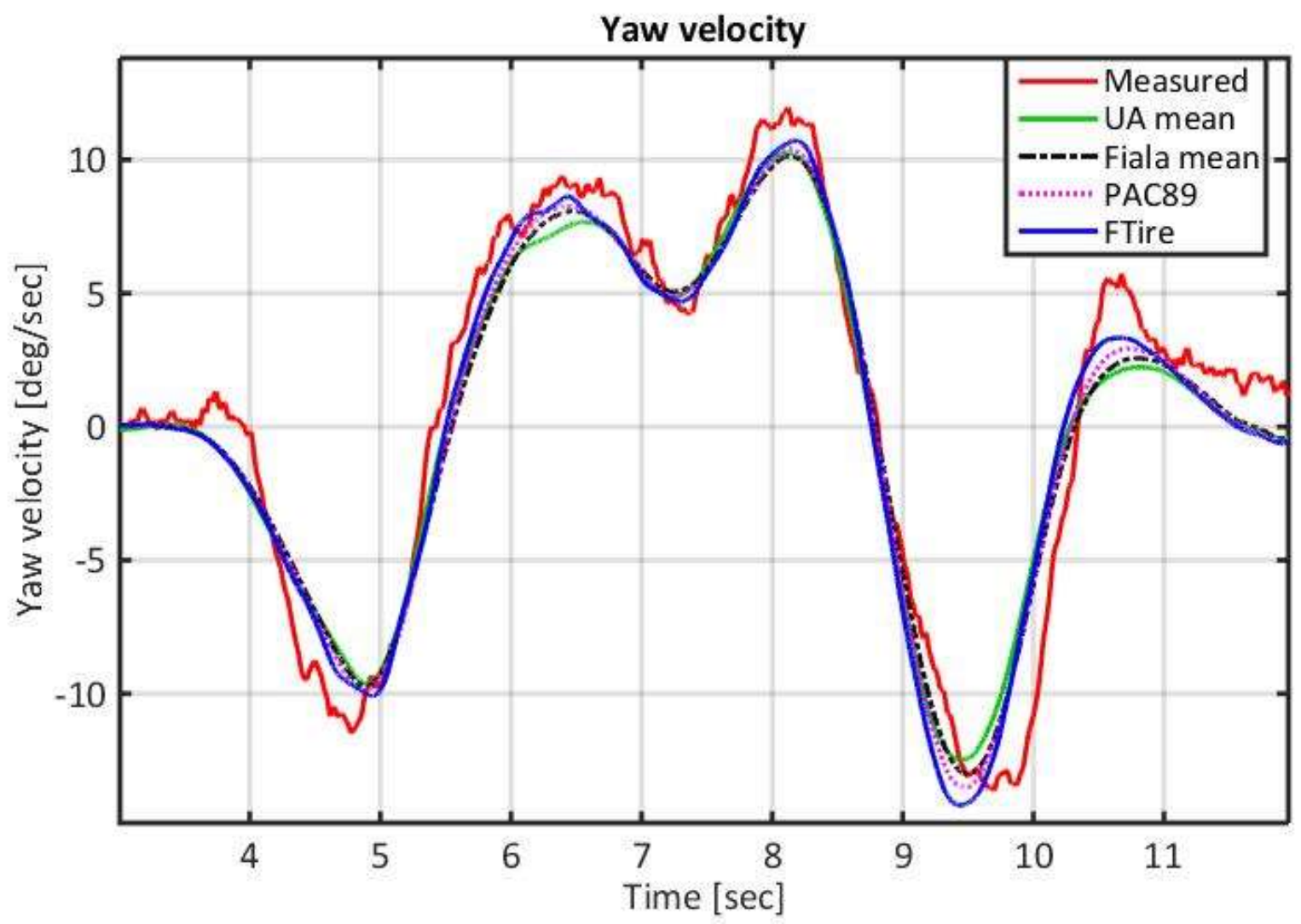

Figure 6: Yaw velocity of the trailer during the DLC test 
Figure 6 indicates that all the tyre models show excellent yaw velocity correlation.

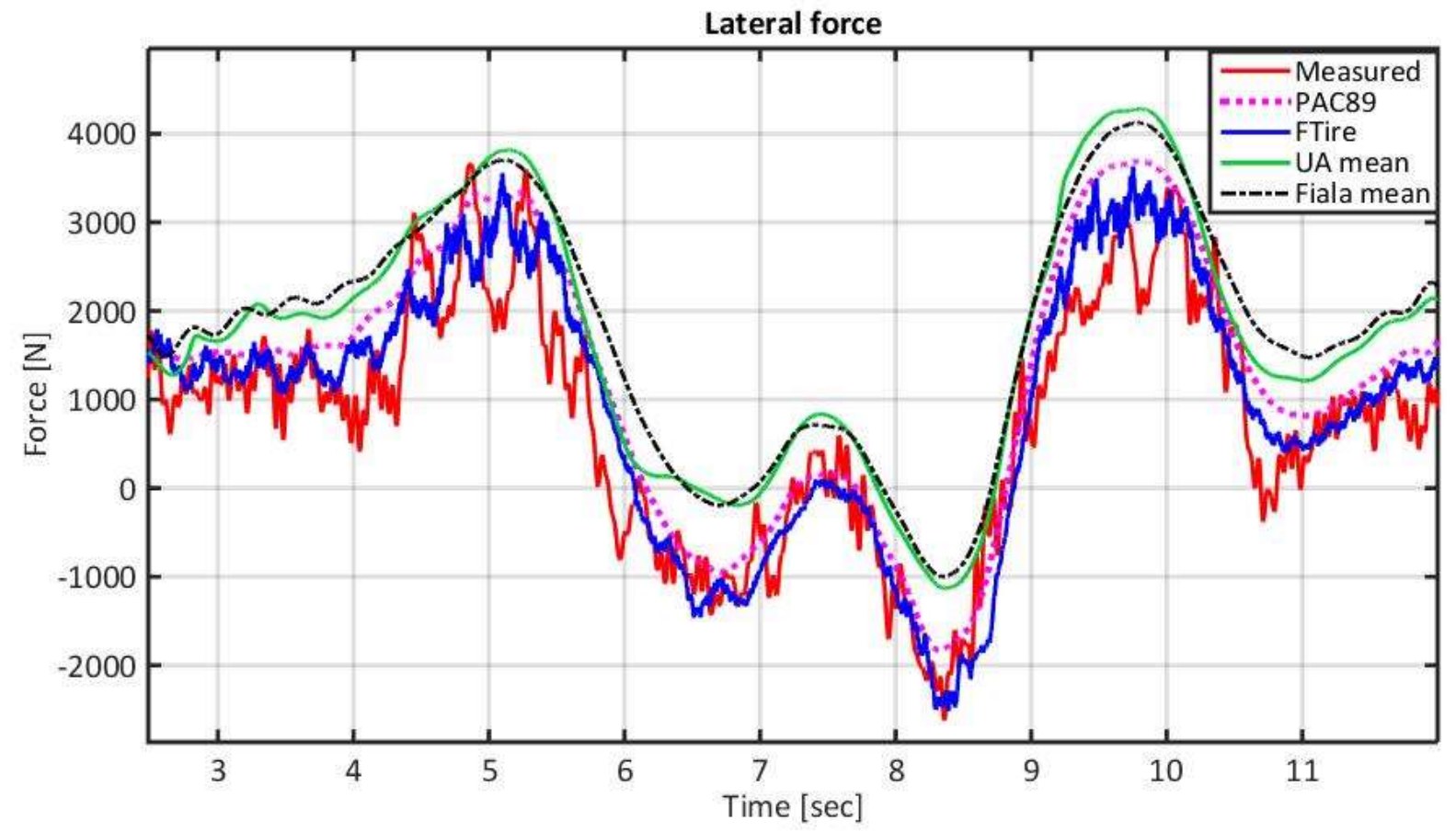

Figure 7: Lateral Force during the DLC

Lateral force correlation is shown in Figure 7. The FTire model shows the best correlation between the measured and simulated results. FTire also captures the higher frequency dynamics present in the test data due to tyre hop while the other models give a highly filtered result. The Pacejka 89 tyre model shows a slight offset between the measured and predicted tyre forces. This offset is more pronounced with the UA Tyre and the Fiala tyre model. This behaviour can be explained by the mean cornering stiffness that was used for the models. The vertical load is however lower than the mean test load. Adding to this a lateral acceleration in excess of $3 \mathrm{~m} / \mathrm{s}^{2}$ was reached during the test which results in significant load transfer. The UA Tyre and the Fiala tyre model do not take the change in vertical tyre load into account and thus show poor correlation with the measured results.

In an attempt to improve the accuracy of the models, the cornering stiffness of the UA tyre and the Fiala tyre model were set to the stiffness as determined for the $36 \% \mathrm{LI}$ load case. The results are shown in Figure 8. From the figure it can be seen that the accuracy of the models improved 
with the lower cornering stiffness. The accuracy of the Fiala and UA tyre models therefore depend strongly on the loading condition of the tyre.

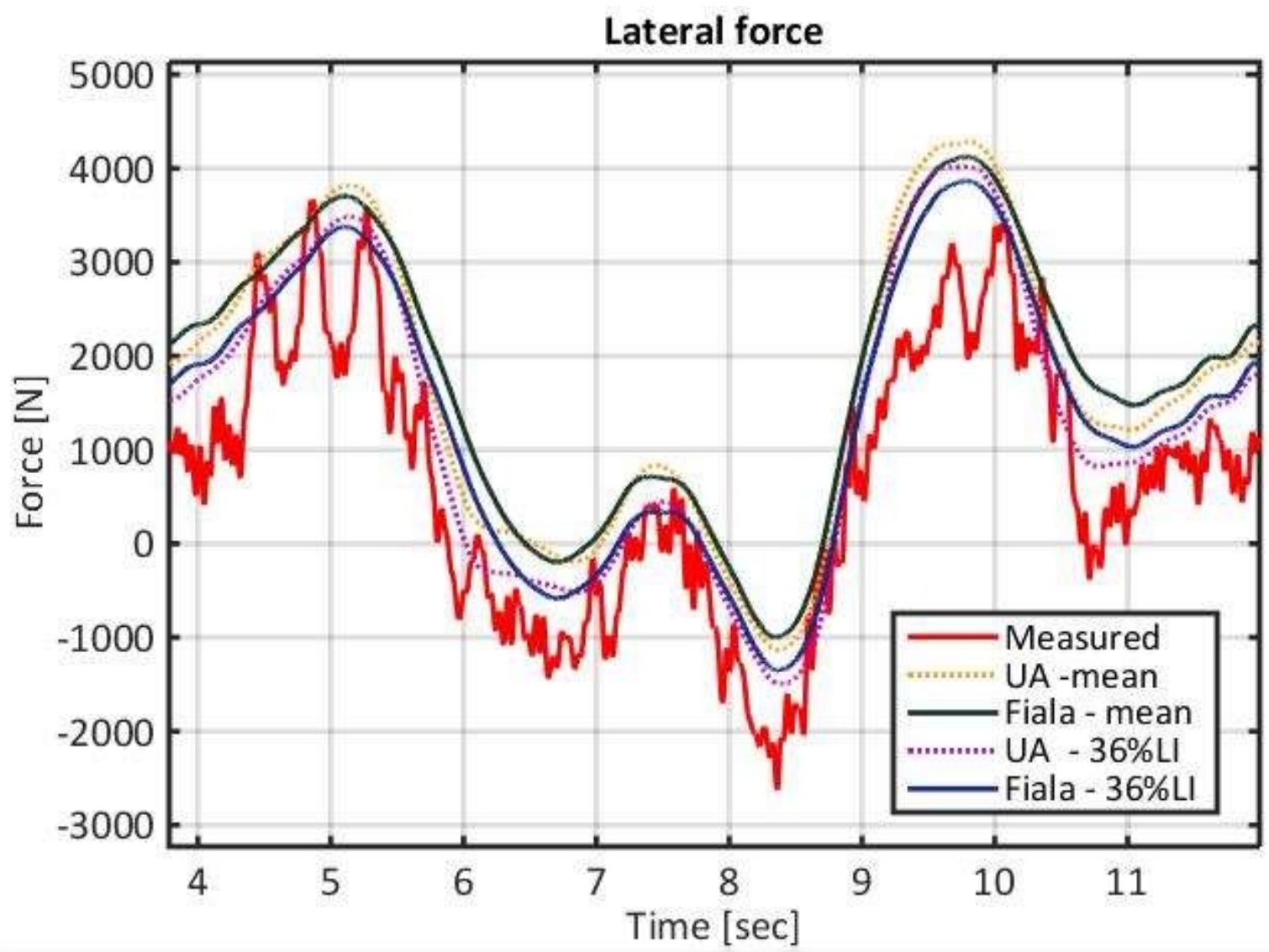

Figure 8: Lateral force for different cornering stiffness

\section{Conclusion}

Extensive side-force versus slip angle characteristics were obtained for the Michelin 16.00 R20 XZL tyre. The test results were used to parameterise Fiala, UA, Pacejka 89 and FTire models for handling. The Fiala and UA tyre models do not take vertical load sensitivity into account and therefore accuracy suffers for varying vertical load conditions. Successful implementation of these models require good prior knowledge of the operating load and test results close to the operating conditions. 
The Pacejka 89 tyre model accounts for a change in vertical load. The model was parameterised successfully to accurately predict the tyre behaviour for all test conditions.

The FTire model was successfully parameterised using FTire/fit and manual tuning. The model was capable to accurately predict the side-force slip behaviour for all three load cases. It also captures higher frequency phenomena that is also visible in the measured data.

On the double lane change tests the Fiala, UA tyre and Pacjeka 89 models showed good correlation but had an offset to the measured results. The low slip-angles, encountered in the double lane change, contributed to the good performance of the Fiala and UA tyre models. However if higher slip-angles and more load transfer were to be encountered, the Fiala and UA tyre models would fail to represent the tyre accurately. The tests also show that the accuracy of the Fiala and UA Tyre models are greatly dependent on the vertical load.

The most accurate lateral tyre behaviour was predicted by the FTire model. The model is shown to predict the tyre behaviour accurately for a wide range of operating conditions. The parameterisation of this tyre model was however the most time consuming and it is the most computationally expensive model.

\section{References}

[1] Haney, P., 2003, The racing and high performance tire. 1st ed. United States of America: Infotire and SAE. pp. 111.

[2] Pacejka, H.B., 2006, Tire and Vehicle Dynamics. 2nd ed. USA: SAE International. 
[3] VMI Group | Force and moment testing, 2014, VMI Group / Force and moment testing.

[ONLINE] Available at: http://www.vmi-group.com/tire/products/tire-and-compound-testing/forceand-moment-testing/. [Accessed 11 March 2014].

[4] Flat-Trac® Tire Test Systems, 2005, 1st ed. [pdf] Eden Prairie: MTS Systems Corporation, pp.4\&12. Available at: http://www.mts.com/en/products/producttype/test-systems/simulationsystems/tire/flat-trac/DEV_002227 [Accessed 6 September 2014].

[5] Kutzbach, H.D., Witzel, P. and Schreiber, M., 2009, Single wheel field tester for farm tractor tyres a review, In: $11^{\text {th }}$ European Regional Conference of the International Society for TerrainVehicle-Systems. Bremen: ISTVS, pp.1-18.

[6] ADAMS View HELP, 2012, California: MSC Software Corporation.

[7] Bakker, E., Pacejka, H.B. and Lidner, L., 1989, A New Tire Model with Application in Vehicle Dynamic Studies. SAE Technical paper, 890087, pp. 101-113.

[8] Gipser M., 1999, FTire a new fast tyre model for ride comfort simulations. In: 1999 international and 14th European ADAS user conference.

[9] Gipser M. The FTire tire model family [viewed 02.07.13, from http://www.cosin.eu/literature].

[10] Stallmann, M.J. and Els, P.S., 2014, Parameterization and modelling of large off-road tyres for ride analyses: Part 2 - Parameterization and validation of tyre models, J Terramechanics, 55 (2014) pp. 85-94 
[11] Stallmann, M.J., Els, P.S. and Becker, M.J., 2014, Parameterization and modelling of large off-road tyres for ride analyses: Part 1 - Obtaining parameterization data, J Terramechanics, 55 (2014) pp. 73-84

[12] Correvit® S-HR Sensors, 2012, 1st ed. [pdf] Winterthur, Switzerland: Kistler Group, p.1. Available at: http://www.corrsys-datron.com/Support/Data_Sheets/CSHRA_000-806e.pdf [Accessed 6 September 2014].

[13] GEROTEK, 2013, GEROTEK. [ONLINE] Available at:http://www.armscordi.com/SubSites/Gerotek1/GEROTEK02_03_019.asp. [Accessed 02 December 2013].

[14] Blundell, M. and Harty, D., 2004. The Multibody Systems Approach to Vehicle Dynamics. 1st ed. USA: SAE.

[15] INTERNATIONAL ORGANISATION FOR STANDARDISATION, 1999, ISO 3888-1:1999(E). Passenger cars - Test track for a severe lane change manoeuvre - Part1: Double lane-change. Geneva:ISO.

[16] VBOX III 100Hz GPS Data Logger - User Guide, 2011,17th ed. [pdf] Buckingham: Racelogic Ltd, p.20. Available at:

http://www.racelogic.co.uk/_downloads/vbox/Manuals/Data_Loggers/RLVB3_Manual\%20\%20English.pdf [Accessed 14 Sep. 2014]. 